\title{
What Have We Learned from Structural Models?
}

\author{
By RICHARD BLUNDELL*
}

At a broad level, a structural economic model is one where the structure of decision making is fully incorporated in the specification of the model. By specifying the parameters that describe the preferences and constraints of the decision-making process, structural models deliver counterfactual predictions. The ability to provide policy counterfactuals sets them apart from reduced-form models. ${ }^{1}$ But the detailed description of the decision-making problem will typically place tougher requirements on measurement and rely, in part, on stronger assumptions.

Structural models aim to identify three distinct, but related, objects: (i) structural "deep" parameters: e.g., Frisch and Marshallian elasticities; (ii) underlying mechanisms: e.g., partial and self-insurance; (iii) policy counterfactuals: e.g., ex ante tax policy evaluations. It is useful, therefore, to distinguish between "full-structural" dynamic models and quasi- (or semi-) structural models, the latter identifying a subset of parameters and/or mechanisms rather than full counterfactuals.

The focus in this paper is on structural microeconometric models for policy analysis. Emphasis is given to models that minimize assumptions on the structural function of interest and on unobserved heterogeneity; and to approaches that align moments from structural and "reduced form" approaches. The discussion

\footnotetext{
* University College London and Institute for Fiscal Studies, Gower Street, London WC1E6BT, UK (e-mail: r.blundell@ucl.ac.uk). I am grateful to Lars Hansen for helpful comments and to Orazio Attanasio, Michael Keane, Costas Meghir, and Ariel Pakes for helpful discussions on related work. This research is part of the ESRC Centre for the Microeconomic Analysis of Public Policy at IFS. I would like to thank the ESRC and the ERC under project MicroConLab for financial support.

${ }^{\dagger}$ Go to https://doi.org/10.1257/aer.p20171116 to visit the article page for additional materials and author disclosure statement.

${ }^{1}$ Hurwicz (1962) defines structural models in terms of invariance to the counterfactual experiments they are designed to address.
}

is limited to single agent models omitting, for space reasons, the many important contributions that use equilibrium concepts, network interactions, and market structure to help secure identification. The goal throughout is to highlight the use of structural models to improve our understanding of observed behavior and to provide reliable policy counterfactuals.

The following sections of the paper draw on work in three related areas. Section I: revealed preference and unobserved heterogeneity; Section II: discrete choice models and welfare reform; and Section III: dynamic structural models and human capital investments. These are areas that have extensive policy applications where structural functions and policy counterfactuals are well defined; that ask well-formulated questions, e.g., ex ante impact of taxes, prices and wages, and optimal design; that analyze static choice and dynamic choice; and, that use new data, new methods, and new computational developments. Section IV concludes.

\section{Revealed Preference and Heterogeneity}

The structure of economic decision-making models delivers restrictions that can be used to recover counterfactuals. For example, the revealed preference (RP) conditions of consumer choice theory can be used to place bounds on consumer responses to new prices and incomes enabling us to examine the impact counterfactual tax and redistributive policies (Blundell, Browning, and Crawford 2008). Recent studies have extended these results to structural models of habits (Crawford 2010) and collective family labor supply (Cherchye, De Rock, and Vermeulen 2011), as well as other deviations from simple RP.

Consider a simple structural demand function: $y=g(p, I, z, u)$ that describes demand for $\operatorname{good}(\mathrm{s}) y$ by consumer $(z, u)$ facing prices and income $(p, I)$. RP inequalities summarize structural information and can be used to bound (set identify) individual demand counterfactuals. An 
additive specification for unobserved heterogeneity $u$ is implausible in consumer models. With non-separable $u$ and monotonicity, conditional nonparametric quantiles can be shown to identify individual structural demands (see Blundell, Kristensen, and Matzkin 2014) ${ }^{2}$ With multivariate heterogeneity only certain features of average welfare contrasts are identified (see Hausman and Newey 2016). The conditional independence assumption on $u$ may also be relaxed to allow for endogeneity of prices $p$ (see Blundell, Horowitz, and Parey forthcoming). That study also provides new insights and policy counterfactuals for individual gasoline demand, highlighting the empirical value of RP restrictions.

\section{Discrete Choice and Welfare Reform}

Structural discrete choice models have been the workhorse of the empirical analysis of welfare-benefit reform. The plethora of welfare-benefit and tax proposals, and actual reforms, that surfaced in the late 1980s and 1990s gave new impetus to their development. Well-specified models incorporate choices not only over part-time and full-time work but also over different welfare and tax credit programs, allowing for stigma costs and accounting for the complicated nonlinear budget constraints that reflect the important overlaps of the many welfare programs, tax credits, and personal taxes.

This area is ideal for examining the role of structural models in policy analysis. Using the Mirrlees Review of tax reform as an example, Blundell (2012) identifies the following five key steps in assembling the foundations for empirical policy research: (i) uncovering the margins of adjustment; (ii) measuring effective incentives; (iii) understanding the importance of information and complexity; (iv) estimating behavioral responses; and (v) counterfactual policy simulation and optimal design. Structural models are center-ground in policy research, entering directly into steps (iv) and (v), but steps (i)-(iii) are also essential for a well-specified model and reliable policy advice.

Step (i) examines the key margins of adjustment. For example, the margins of labor market

\footnotetext{
${ }^{2}$ With multiple demands, invertibility in $u$ is not sufficient for identification (see Matzkin 2007).
}

adjustment for tax and welfare policy analysis. Blundell, Bozio, and Laroque (2011) show the importance of a lifetime view of employment and hours with key differences between extensive and intensive margins that are accentuated at particular ages for different education groups.

Next comes step (ii), the measurement of effective incentives. An advantage of structural models is the requirement for a precise statement of constraints. For tax and welfare policy this requires a detailed institutional knowledge of overlapping taxes, tax credits, and welfare benefits. As the careful studies in Moffitt (2016) show, modern tax and welfare-benefit systems are complex with many overlapping welfare benefits and taxes. If we are to accurately recover preferences we need to understand not only these overlaps but also the salience of the various tax and welfare benefit incentives. This is step (iii) and requires a careful modeling of welfare program participation among eligible families.

It is only after having built a clear picture from these first three steps that the rigorous econometric analysis of structure and causality comes into play. At step (iv) an eclectic mix of reduced form and structural approaches is to be preferred. There is a strong complementarity between these approaches. Quasi-experimental evaluations can provide robust measures of certain policy impacts but are necessarily local and limited in scope. Structural estimation allows counterfactual policy simulations which can then feed into a policy (re-)design analysis in $\operatorname{step}(\mathrm{v})$.

Structural discrete choice models have been used extensively to assess the impact of means-tested welfare programs, tax credits, and potential reforms to them, see Blundell and Hoynes (2004). These policies are directed at relatively poor families with low labor market attachment and low earnings. Policy counterfactuals are required as these reform proposals typically involve non-marginal changes to the tax credit and welfare system. ${ }^{3}$

The key elements of a structural model for welfare reform (see Keane and Moffitt 1998)

\footnotetext{
${ }^{3}$ For marginal policy reform, semi-structural models are often sufficient and use robustly estimated local derivatives of structural functions, as in Chetty (2009).
} 
involve a precise definition of the budget constraint, with all the tax/tax credit and benefit interactions. The specification of preferences over different hours and program options that give rise to multinomial choice across discrete hours and welfare combinations. Heterogeneity is essential, reflecting observed differences across families through measured demographics, and unobservable differences in "tastes" for work, stigma costs, childcare costs, and fixed costs of work.

There are many examples of where these models perform well, their ex ante predictions matching post-reform behavior (see Blundell 2012). In the more convincing examples, identification is based on sources of plausibly exogenous variation in welfare and tax rules across time and locations. The models have also proven invaluable for counterfactual evaluations of alternative policies and have been used to examine optimal design (see Blundell and Shephard 2012). These models identify wage and income elasticities at the extensive and intensive margins across different demographic groups, proving a secure basis for targeting earned income tax expansions at low-income families. Complexity and overlapping benefit withdrawal rates are clearly inefficient and inhibit take-up, providing a clear motivation for the integration of benefits and tax credits (see Brewer, Saez, and Shephard 2011).

Recent studies seek to further relax the assumptions on preferences in structural models of labor supply and taxation, using only use only the restrictions from revealed preference to identify some key parameters of interest. For example, Blomquist et al. (2015) estimate the conditional mean of taxable income imposing revealed preference restrictions and allowing for measurement errors. This work aims at a robust measure of the structural taxable income function rather than identifying the full optimization problem. Manski (2014) develops conditions where partial prediction of tax revenue under proposed policies and partial knowledge of the welfare function for utilitarian policy evaluation is feasible.

There remain many areas where structural models in the field are in need of further refinement. Human capital investment, persistent wage shocks, and search frictions add potentially valuable dynamic considerations, to which we now turn.

\section{Dynamic Structural Models}

Identification of structural models in a dynamic optimizing environment requires strong assumptions on subjective discount rates and the distribution of beliefs. For example, building on the original work by Rust (1994), Magnac and Thesmar (2002) show that in discrete choice settings the utility functions in each alternative cannot be (nonparametrically) identified without external information on the distribution of unobserved preference shocks and the discount rate, (see also Arcidiacono and Miller 2011).

The upshot is that particular care needs to be taken in specifying, estimating, and validating dynamic structural models. One reaction is to focus on a subset of structural parameters that are more robustly identified. As already noted, one can view this as a "semi" or "quasi" structural approach. For example, one may estimate "life-cycle" consistent preferences by conditioning on consumption (or net saving) (see Blundell and Walker 1986). Another example is the partial insurance literature (see Blundell, Pistaferri, and Preston 2008). Even so, these quasi-structural approaches are not robust to intertemporal non-separability that occurs in models incorporating human capital decisions. For this we need a fully specified structural model.

The groundbreaking work in the development of structural models of life-cycle labor supply choices was carried out by Heckman and MaCurdy (1980), subsequently developed for discrete choice decisions and integrated with human capital choices by Keane and Wolpin (1997) among others. That work uncovered key differences between short-run and longer-run responses to wage changes and found that, once human capital choices are incorporated, estimated labor supply responses from static models can be quite misleading.

The advantage of these structural models is that they identify life-cycle counterfactuals and mechanisms, e.g., the impact of tax reforms and the "insurance value" of redistributive policies. As a recent example, consider the Blundell et al. (2016) application to education choices, experience capital and female labor supply. That study uses panel data and the time series of tax, tax credit, welfare, and tuition reforms in the United Kingdom to identify the structural parameters of human capital and labor supply choices, conditioning on early life-history variables. 
At the heart of the structural model is a dynamic wage equation estimated jointly with education and life-cycle labor supply decisions. This features a concave work experience term on wages and persistent shocks. The structural model fit is shown to be good. But this is only achieved by allowing returns to work experience to differ by education level, by conditioning on extensive background factors, and by including a part-time work penalty in experience capital.

The results from this structural model deliver some key new insights: (i) structural parameters: experience effects display strong dynamic complementarity, with lower experience effects for the low educated and for those in part-time work; (ii) mechanisms: the insurance value of tax credits is a substantial part of welfare gain; and (iii) counterfactuals: lower education women with young kids have larger supply responses, implying tax credits can be an optimal design, although they induce little earnings progression. There are also found to be significant, but small, effects of tax credit expansion on education choice, attenuating some of the employment gains.

As a by-product the structural model allows a reconciliation of past results. That is it can help explain past (static) structural and quasi-experimental results. Human capital complementarity and the part-time work penalty imply negligible experience capital wage dynamics for low-educated women, explaining why static discrete models that accounted for detailed tax and benefit interactions performed well for low-income households.

There are many other important recent contributions to the structural modeling of dynamic life-cycle choices-too many to discuss in detail. Key examples include: Cunha, Heckman, and Schennach (2010) who provide important new results on the identification and estimation of the "household production" of early years skill formation; French (2005) which shows the key role of retirement incentives separate from preferences at retirement; Meghir, Low, and Pistaferri (2015) who separate employment risk from wage risk; and Low and Pistaferri (2016) who examine the dynamic incentives in the disability system. All of these studies provide convincing evidence on key structural parameters and counterfactuals, helping build our knowledge base on life-cycle behavior.

\section{Conclusions}

Structural models play a key role in understanding economic behavior and in policy design. They complement reduced form and experimental approaches by explicitly incorporating restrictions from economic decision-making models. By doing so they make three related, but distinct, contributions: they identify "deep" structural parameters; they provide a clear insight into the mechanisms underlying the observed behavior; and they provide counterfactuals. In addition, they can be used to reconcile earlier results and consequently help build a knowledge base for policy research.

Structural models make explicit the assumptions on preferences and constraints being used to estimate parameters, mechanisms, and counterfactuals. These assumptions need to be tested, assessed, and relaxed wherever possible. This has been the theme taken here, focusing on the structural analysis of labor supply and consumer behavior. Reliable structural analyses in these areas acknowledge the importance of aligning moments from structural models with reduced form evidence and minimizing the reliance on unnecessary assumptions.

An important recent development has been applications which combine structural and experimental evidence. For example, Todd and Wolpin (2006) use experimental data to validate a dynamic structural model of child schooling and fertility. Attanasio, Meghir, and Santiago (2012) use experimental data to estimate general equilibrium effects. Karlan and Zinman (2009) use a consumer credit experiment to distinguish between adverse selection and moral hazard. Duflo, Hanna, and Ryan (2012) design an experiment to identify the impact of monitoring and financial incentives on teacher absence and on learning.

I leave the final words to Frisch $(1933$, p. 2) "No amount of statistical information, however complete and exact, can by itself explain economic phenomena. ... we need the guidance of a powerful theoretical framework. Without this no significant interpretation and coordination of our observations will be possible."

\section{REFERENCES}

-Attanasio, Orazio P., Costas Meghir, and Ana Santiago. 2012. "Education Choices in Mexico: 
Using a Structural Model and a Randomized Experiment to Evaluate PROGRESA." Review of Economic Studies 79 (1): 37-66.

-Arcidiacono, Peter, and Robert A. Miller. 2011. "Conditional Choice Probability Estimation of Dynamic Discrete Choice Models with Unobserved Heterogeneity." Econometrica 79 (6): 1823-67.

Blomquist, Soren, Anil Kumar, Che-Yuan Liang, and Whitney K. Newey. 2015. "Individual Heterogeneity, Nonlinear Budget Sets, and Taxable Income." CESifo Group Working Paper 5320.

- Blundell, Richard. 2012. "Tax Policy Reform: The Role of Empirical Evidence." Journal of the European Economic Association 10 (1): 43-77.

Blundell, Richard, Antoine Bozio, and Guy Laroque. 2011. "Extensive and Intensive Margins of Labour Supply: Working Hours in the US, UK and France." Institute for Fiscal Studies Working Paper W11/01.

- Blundell, Richard, Martin Browning, and Ian Crawford. 2008. "Best Nonparametric Bounds on Demand Responses." Econometrica 76 (6): 1227-62.

- Blundell, Richard, Monica Costa Dias, Costas Meghir, and Jonathan Shaw. 2016. "Female Labor Supply, Human Capital, and Welfare Reform." Econometrica 84 (5): 1705-53.

Blundell, Richard, Joel Horowitz, and Matthias Parey. Forthcoming. "Nonparametric Estimation of a Heterogeneous Demand Function under Slutsky Inequality Restrictions. Review of Economics and Statistics.

Blundell, Richard, and Hilary Hoynes. 2004. "Has "In-Work" Benefit Reform Helped the Labor Market?" In Seeking a Premier Economy: The Economic Effects of British Economic Reforms, 1980-2000, edited by David Card, Richard Blundell, and Richard B. Freeman, 411-59. Chicago: University of Chicago Press.

- Blundell, Richard, Dennis Kristensen, and Rosa Matzkin. 2014. "Bounding Quantile Demand Functions Using Revealed Preference Inequalities." Journal of Econometrics 179 (2): 11227.

Blundell, Richard, Luigi Pistaferri, and Ian Preston. 2008. "Consumption Inequality and Partial Insurance." American Economic Review 98 (5): 1887-1921.

- Blundell, Richard, and Andrew Shephard. 2012. "Employment, Hours of Work and the Optimal
Taxation of Low-Income Families." Review of Economic Studies 79 (2): 481-510.

- Blundell, Richard, and Ian Walker. 1986. "A Life-Cycle Consistent Empirical Model of Family Labour Supply Using Cross-Section Data." Review of Economic Studies 53 (4): 539-58.

Brewer, Mike, Emmanuel Saez, and Andrew Shephard. "Means-Testing and Tax Rates on Earnings." In Dimensions of Tax Design: The Mirrlees Review, edited by James Mirrlees, Stuart Adam, Timothy Besley, Richard Blundell, Stephen Bond, Robert Chote, Malcolm Gammie, Paul Johnson, Gareth Myles, and James Poterba, 90-173. Oxford: Oxford University Press.

-Cherchye, Laurens, Bram De Rock, and Frederic Vermeulen. 2011. "The Revealed Preference Approach to Collective Consumption Behaviour: Testing and Sharing Rule Recovery." Review of Economic Studies 78 (1): 17698.

-Chetty, Raj. 2009. "Sufficient Statistics for Welfare Analysis: A Bridge between Structural and Reduced-Form Methods." Annual Review of Economics 1 (1): 451-87.

-Crawford, Ian. 2010. "Habits Revealed." Review of Economic Studies 77 (4): 1382-1402.

-Cunha, Flavio, James J. Heckman, and Susanne M. Schennach. 2010. "Estimating the Technology of Cognitive and Noncognitive Skill Formation." Econometrica 78 (3): 883-931.

-Duflo, Esther, Rema Hanna, and Stephen P. Ryan. 2012. "Incentives Work: Getting Teachers to Come to School." American Economic Review 102 (4): 1241-78.

-French, Eric. 2005. "The Effects of Health, Wealth, and Wages on Labour Supply and Retirement Behaviour." Review of Economic Studies 72 (2): 395-427.

Frisch, Ragnar. 1933. “Editor's Note." Econometrica 1 (1): 1-4.

-Hausman, Jerry A., and Whitney K. Newey. 2016. "Individual Heterogeneity and Average Welfare." Econometrica 84 (3): 1225-48.

-Heckman, James J., and Thomas E. MaCurdy. 1980. "A Life Cycle Model of Female Labour Supply." Review of Economic Studies 47 (1): 47-74.

Hurwicz, Leonid. 1962. "On the Structural Form of Interdependent Systems." In Logic, Methodology, and Philosophy of Science: Proceedings of the 1960 International Congress, edited by 
Ernest Nagel, Patrick Suppes, and Alfred Tarski, 232-39. Stanford, CA: Stanford University Press.

- Karlan, Dean, and Jonathan Zinman. 2009. "Observing Unobservables: Identifying Information Asymmetries with a Consumer Credit Field Experiment." Econometrica 77 (6): 1993-2008.

-Keane, Michael, and Robert Moffitt. 1998. "A Structural Model of Multiple Welfare Program Participation and Labor Supply." International Economic Review 39 (3): 553-89.

-Keane, Michael P., and Kenneth I. Wolpin. 1997. "The Career Decisions of Young Men." Journal of Political Economy 105 (3): 473-522.

-Low, Hamish, Costas Meghir, and Luigi Pistaferri. 2010. "Wage Risk and Employment Risk over the Life-Cycle." American Economic Review 100 (4): 1432-67.

LLow, Hamish, and Luigi Pistaferri. 2015. "Disability Insurance and the Dynamics of the Incentive-Insurance Trade-Off." American Economic Review 105 (10): 2986-3029.

-Magnac, Thierry, and David Thesmar. 2002. "Identifying Dynamic Discrete Decision Processes." Econometrica 70 (2): 801-16.
-Manski, Charles F. 2014. "Identification of Income-Leisure Preferences and Evaluation of Income Tax Policy." Quantitative Economics 5 (1): 145-74.

Matzkin, Rosa L. 2007. "Heterogeneous Choice." In Advances in Economics and Econometrics: Theory and Applications, Ninth World Congress, Volume III, edited by Richard Blundell, Whitney K. Newey, and Torsten Persson, 75-110. Cambridge, UK: Cambridge University Press.

Moffitt, Robert. 2016. Economics of MeansTested Transfer Programs in the United States. Chicago: University of Chicago Press.

Rust, John. 1994. "Estimation of Dynamic Structural Models, Problems and Prospects: Discrete Decision Processes." In Advances in Econometrics, Volume 2, edited by Christopher A. Sims, 119-70. Cambridge, UK: Cambridge University Press.

Todd, Petra, and Kenneth Wolpin. 2006. "Assessing the Impact of a School Subsidy Program in Mexico: Using a Social Experiment to Validate a Dynamic Behavioral Model of Child Schooling and Fertility." American Economic Review 96 (5): 1384-1417. 